\title{
Poremećaji gutanja u neuroloških bolesnika
}

\section{Swalloving disorders in neurological patients}

\author{
Nina Čuš ${ }^{*}$, Tatjana Šepić1 ${ }^{1}$ Diana Maržić ${ }^{1}$, Katarina Radobuljac ${ }^{1}$, Vladimira Vuletić ${ }^{2}$
}

${ }^{1}$ Zavod za audiologiju i fonijatriju, Klinički bolnički centar Rijeka, Hrvatska

${ }^{2}$ Klinika za neurologiju, Klinički bolnički centar Rijeka, Hrvatska
Sažetak. Poremećaji gutanja učestala su tegoba kod neuroloških bolesnika. Radi se o tegobama koje znatno narušavaju kvalitetu života, mogu uzrokovati poremećaje hranjenja, malnutriciju, dehidraciju, ali i dovesti do aspiracije i aspiracijske pneumonije. Dostupne dijagnostičke metode obuhvaćaju upitnike za probir i samoprocjenu simptoma, protokole logopedske dijagnostike te fiberendoskopiju i videofluoroskopiju, a važna je i procjena nutritivnog statusa bolesnika. Nakon postavljene dijagnoze disfagije poseže se za brojnim rehabilitacijskim postupcima koji omogućavaju ublažavanje simptoma i smanjenje rizika od aspiracije. Katkad se tegobe pokušava umanjiti i kirurškim metodama. U liječenju disfagije u oboljelih od Parkinsonove bolesti istražuje se i korist od duboke moždane stimulacije.

Ključne riječi: disfagija; neurološki poremećaji; poremećaji gutanja

Abstract. Swallowing disorders are common among neurological patients. They can significantly impair the quality of life, cause eating disorders, malnutrition, dehydration, and increase the risk of aspiration and aspiration pneumonia. Available diagnostic methods include questionnaires for screening of dysphagia symptoms, speech therapy diagnostic protocols, fiberoendoscopy and videofluoroscopy. It is also important to assess the patient's nutritional status. Plenty of rehabilitation procedures are available for the relief of symptoms and reduction of the risk of aspiration. Surgical methods are sometimes used in the process of treatment. The benefits of deep brain stimulation are being investigated in the treatment of dysphagia in Parkinson's disease patients.

Key words: dysphagia; neurological disorders; swallowing disorders

\author{
*Dopisni autor: \\ Nina Čuš, dr. med. \\ Zavod za audiologiju i fonijatriju, \\ Klinički bolnički centar Rijeka, \\ Krešimirova 42, 51000 Rijeka, Hrvatska \\ E-mail: nina.cus95@gmail.com
}




\section{UVOD}

Disfagija je u neuroloških bolesnika vrlo učestali simptom. Ovisno o vrsti neurološke bolesti može nastupiti naglo ili postupno, odnosno narušiti proces gutanja na različitim razinama. Narušena funkcija gutanja vodi do brojnih mogućih komplikacija poput aspiracije, aspiracijske pneumonije, malnutricije, a generalno narušava i kvalitetu života bolesnika. Zbog svega navedenog, važna je pravovremena dijagnostika i tretman disfagije $u$ neuroloških bolesnika ${ }^{1}$. Ovaj rad daje pregled neuroloških bolesti i stanja koja mogu dovesti do nastanka disfagije, osnove patofizioloških procesa koji je uzrokuju, kao i pregled dostupnih dijagnostičkih i terapijskih metoda kojima navedeni bolesnici mogu biti podvrgnuti.

\section{FIZIOLOGIJA GUTANJA}

Gutanje je složena fiziološka funkcija kojom se bolus sažvakane hrane prenosi od usne šupljine do želuca, zaobilazeći pritom larinks i dišne puteve. Tradicionalno se može podijeliti u tri faze: oralnu ili voljnu fazu te faringealnu i ezofagealnu fazu koje su dominantno nevoljne. $U$ kontrolu procesa gutanja uključene su brojne neuroanatomske strukture koje, koordinirajući rad jezika, facijalnih, žvačnih, faringealnih, laringealnih i ezofagealnih mišića, omogućavaju siguran proces gutanja. Motorna i osjetna inervacija struktura uključenih u gutanje odvijaju se putem V, VII, IX, X i XI moždanog živca, dok je XII moždani živac zadužen isključivo za motornu inervaciju mišića jezika. U nadzor procesa gutanja uključene su i više kortikalne strukture ${ }^{1,2}$.

\section{NEUROGENA OROFARINGEALNA DISFAGIJA}

Otežan prijenos tekućeg ili krutog sadržaja od usne šupljine do želuca, odnosno otežano gutanje, naziva se disfagijom ${ }^{3}$. Disfagija je u neuroloških bolesnika vrlo čest simptom, a može nastati kao posljedica bilo koje bolesti ili oštećenja u dijelu živčanog sustava zaduženog za gutanje. Patofiziološki gledano, oštećenje neuroloških puteva može dovesti do disfagije na više načina, a neki od njih uključuju slabljenje pokreta i koordinacije jezika, slabljenje žvačne ili ostale muskulature uključene u proces gutanja, nedovoljnu osjetlji- vost receptora bukalne i faringealne sluznice itd. Svaka disfagija uzrokovana neurološkim oštećenjem ili bolešću naziva se neurogenom orofaringealnom disfagijom ${ }^{4-6}$.

\section{UZROCI NEUROGENE OROFARINGEALNE} DISFAGIJE

\section{Cerebrovaskularne bolesti - moždani udar}

Moždani se udar u brojnoj literaturi ističe kao vodeća i najznačajnija cerebrovaskularna bolest

Poremećaji gutanja učestala su tegoba kod neuroloških bolesnika. Neprepoznati ili neliječeni mogu dovesti do brojnih komplikacija poput aspiracije, aspiracijske pneumonije, malnutricije i dehidracije. Testovima probira moguće je brzo detektirati bolesnike s povećanim rizikom od disfagije, čime se ubrzava postavljanje dijagnoze i provođenje potpornih mjera liječenja i rehabilitacije.

koja može biti uzrokom neurogene orofaringealne disfagije ${ }^{3,7,8}$. Ovisno o izvoru podataka, procjenjuje se kako 8,1 - $80 \%$ bolesnika nakon moždanog udara ima neki oblik teškoća s gutanjem ${ }^{8}$. Simptomi uglavnom nastupaju naglo, a prisutnost disfagije u trenutku prijama bolesnika s moždanim udarom neki autori navode kao neovisan prediktor lošijeg ishoda liječenja ${ }^{3}$.

Disfagiju osim moždanog udara na razini moždanog debla i produljene moždine, može uzrokovati i moždani udar na cerebralnoj ili cerebelarnoj razini, a lokalizacija lezije u području produljene moždine uglavnom uzrokuje teže smetnje gutanja od ostalih lokalizacija. Ovisno o lokalizaciji i veličini lezije, uz disfagiju se mogu javiti i brojni popratni simptomi poput afazije, apraksije, disartrije, laringealne i faringealne paralize $\mathrm{e}^{1,3-5,9}$.

U ranom razdoblju nakon preboljenog moždanog udara aspiracijska pneumonija predstavlja vodeći uzrok lošijeg ishoda liječenja, produljenog razdoblja hospitalizacije i povećanog mortaliteta ${ }^{4,7,10}$. Ona se javlja u prvih sedam dana nakon preboljenog moždanog udara i zahvaća oko 14 \% bolesni$\mathrm{ka}^{10}$, a smatra se kako su joj oni koji imaju smetnje gutanja oko tri puta skloniji?

Vremenom simptomi otežanog gutanja mogu djelomično ili potpuno regredirati, dok su u dru- 
gim slučajevima posljedice trajne $e^{3,4,7}$, a šest mjeseci nakon preboljenog moždanog udara teškoće s gutanjem zaostaju u 11 - $50 \%$ bolesnika ${ }^{3,7}$. Jedna je retrospektivna studija proučavala poveznicu disfagije s pojavnošću pneumonije i mortalitetom bolesnika godinu dana nakon moždanog udara. U grupu bolesnika s disfagijom svrstani su oni kod kojih je dva ili više puta postojala potreba za postavljanjem nazogastrične sonde, a obuhvaćena su ukupno 5032 bolesnika s disfagijom i 52,323 bolesnika u kontrolnoj grupi. Rezultati su pokazali kako je prva dva tjedna nakon moždanog udara incidencija pneumonije bila slična u objema grupama, dok je godinu dana nakon moždanog udara incidencija pneumonije bila veća u grupi bolesnika s disfagijom $(18,78 \%$ u odnosu na $6,52 \%, p<0,001)$. Također, mortalitet je bio veći u skupini bolesnika s disfagijom $(10,45 \% \mathrm{u}$ odnosu na 4,77\%, $p<0,001$ ) godinu dana nakon moždanog udara. Razlike u pojavnosti pneumonije i mortaliteta nastavile su rasti između ovih dviju skupina i nakon petogodišnjeg perioda praćenja ${ }^{11}$. Stoga je u zbrinjavanju bolesnika s moždanim udarom izuzetno važno voditi računa o što ranijoj dijagnostici disfagije i njezinom tretmanu, čime je moguće smanjiti izglede za razvoj aspiracijske pneumonije, a time i poboljšati izglede liječenja ${ }^{10}$.

\section{Ekstrapiramidne bolesti - Parkinsonova bolest}

Problem disfagije u oboljelih od Parkinsonove bolesti ističe se zbog visoke prevalencije Parkinsonove bolesti u populaciji, ali i zbog visoke zastupljenosti disfagije kao simptoma među oboljelima ${ }^{4,12}$. Procjenjuje se kako teškoće s gutanjem razvije 11 - $80 \%$ ovih bolesnika, a vrijednosti zastupljenosti variraju ovisno o vrsti dijagnostičke metode i definiciji disfagije koja je korištena u istraživanju ${ }^{8}$.

Tijek bolesti je progresivan, a disfagija se pogoršava zajedno s pogoršanjem sveopćeg stanja bolesnika te postaje izraženija u uznapredovalim fazama bolestiti,4,12. Prosječno, simptomi otežanog gutanja postaju izraženiji $10-11$ godina od prve pojave motornih simptoma ${ }^{12}$, a očekivano trajanje života nakon pojave izraženijih simptoma disfagije i dizartrije procjenjuje se na 15- 24 mje$\operatorname{seca}^{13}$.
Patofiziologija disfagije u Parkinsonovoj bolesti uvjetovana je propadanjem dopaminergičkih bazalnih ganglija, ali i degenerativnim procesima koji nastaju zbog nakupljanja Lewyjevih tjelešaca u raznim nedopaminergičkim područjima moždane kore i moždanog debla. Ulogu u degenerativnim procesima igra i nakupljanje alfa-sinukleina $u$ živčanom sustavu ${ }^{12}$.

Zbog hipokinezije žvačnih mišića i jezika usporen je proces žvakanja i prijenosa bolusa prema ždrijelu, a poremećen je i faringealni motilitet zbog čega je faringealna faza gutanja znatno odgođena ${ }^{1,14}$. Oralna faza gutanja može biti dodatno poremećena pojavom tardivne diskinezije uzrokovane terapijom antiparkinsonicima ${ }^{4}$. Osim motornih, prisutni su i ispadi somatosenzorne inervacije dišnog sustava i struktura uključenih u proces gutanja, zbog čega je kod bolesnika smanjena svjesnost o prisutnosti disfagije ${ }^{15}$, a često im je smanjen ili odsutan i refleks kašlja ${ }^{16}$. Većina opisanih patofizioloških mehanizama dovodi i do povećanog rizika od aspiracije u ovih bolesnika ${ }^{16-18}$.

Upravo se aspiracijska pneumonija navodi kao vodeći uzrok hitne hospitalizacije oboljelih od Parkinsonove bolesti u kojih bolest traje dulje od pet godina ${ }^{19}$. Ona je ujedno i vodeći uzrok smrtnosti među oboljelima od Parkinsonove bolesti ${ }^{20-22}$ koji aspiracijsku pneumoniju razvijaju oko dva puta češće od ispitanika u kontrolnoj grupi ${ }^{19}$. Od pneumonije umire i do 33 \% bolesnika s Parkinsonovom bolešću²2.

Prisutnost disfagije u pacijenata s Parkinsonovom bolešću povećava rizik od dehidracije, malnutricije, nemogućnosti uzimanja lijekova i slično ${ }^{12}$.

Kao posebna skupina ističu se bolesnici s atipičnim parkinsonizmom, naročito oni koji boluju od progresivne supranuklearne paralize. U njih simptomi disfagije nastupaju znatno ranije nego $u$ bolesnika s Parkinsonovom bolešću, prosječno 3-4 godine od početka bolesti, a ranija pojava disfagije dovodi se u vezu s lošijim izgledima preživljava$\mathrm{nja}^{1,12,23}$.

\section{Demencije - Alzheimerova bolest}

Dobno standardizirana prevalencija demencija u ljudi koji imaju 60 ili više godina u svijetu iznosi $5-7 \%^{24}$, a zastupljenost problema s gutanjem u tih bolesnika varira od 13 do $57 \%{ }^{25}$. Najzastuplje- 
nija demencija je Alzheimerova demencija, ${ }^{5}$ a iako nedostaje studija na većem uzorku ispitanika, većina dostupnih izvora navodi kako zastupljenost disfagije među oboljelima u poodmaklim stadijima bolesti iznosi preko $84 \%^{26-28}$.

lako je bolest progresivnog karaktera, a simptomi disfagije postaju izraženiji u kasnijim stadijima, disfagija može biti prisutna u svim stadijima Alzheimerove demencije. Katkad, u samim početcima bolesti, simptomi disfagije mogu biti supkliničkog karaktera ${ }^{26,28}$.

Disfagija je karakterizirana produljenim vremenom tranzicije bolusa iz oralne prema faringealnoj fazi i izraženim senzornim deficitom u smislu smanjenog prepoznavanja okusa i mirisa. Motoričke funkcije poput žvakanja, pokreta jezikom i formiranja bolusa manje su narušene ${ }^{28}$. Treba, također, imati na umu kako u ovih bolesnika problem hranjenja može biti uzrokovan i širim spektrom kognitivnih poremećaja koji dovode do smanjene sposobnosti za vizualnim prepoznavanjem hrane i izvođenjem akta gutanja ${ }^{28,29}$.

Oko $44 \%$ ovih bolesnika aspirira u poodmaklim stadijima bolesti ${ }^{30}$, a posljedično često podliježu i pneumoniji. Osim toga, disfagija, uz opisane kompleksne teškoće hranjenja, povećava rizik od malnutricije i dehidracije $e^{4,27}$.

\section{Demijelinizacijske bolesti - multipla skleroza}

Disfagija je učestala tegoba u bolesnika s demijelinizacijskim bolestima. Zastupljenost ove tegobe među oboljelima općenito iznosi oko 43,3\%, a varira od 37,21 do $57,47 \%$ ovisno o tome jesu li za njenu dijagnozu korištene subjektivne ili objektivne metode ${ }^{31}$.

Poremećaji gutanja nastaju zbog demijelinizacijskih lezija u području moždanog korteksa, kortikobulbarnog trakta, moždanog debla, produljene moždine i malog mozga te zbog pareze moždanih živaca ${ }^{32,33}$. Naročitu ulogu u razvoju disfagije imaju poremećaji na razini moždanog debla, a vjerojatnost za pojavu simptoma povećava se $\mathrm{s}$ povećanjem broja zahvaćenih regija u moždanom deblu, kao i sa sveobuhvatnim povećanjem broja demijelinizacijskih lezija ${ }^{33}$.

Tegobe se mogu javljati povremeno u razdobljima relapsa bolesti ili mogu biti trajne kada se radi o progresivnim oblicima bolesti ${ }^{4}$. Zahvaćena može biti oralna, faringealna i ezofagealna faza gutanja $^{32}$, a neka istraživanja ukazuju na to kako je faringealna faza gutanja zahvaćena češće od oralne faze gutanja na statistički značajnoj razi$\mathrm{ni}^{34}$.

Budući da zahvaća mlađu populaciju, multipla skleroza, kao i problemi s gutanjem koji posljedično nastaju, može imati značajan utjecaj na kvalitetu života i radnu sposobnost ovih bolesnika ${ }^{4,35}$. Tako se u istraživanju iz 2018., provedenom na 103 ispitanika s multiplom sklerozom, navodi kako je $60 \%$ bolesnika s disfagijom izjavilo da im problemi s gutanjem predstavljaju smetnju u svakodnevnom životu. Njih $50 \%$ navelo je kako se osjećaju obeshrabreno, frustrirano ili depresivno zbog problema s disfagijom, a $45 \%$ ih je zbog istog problema imalo smanjenu želju za hranom ${ }^{35}$.

U ovih je bolesnika također povećan rizik od aspiracije, aspiracijske pneumonije, malnutricije i dehidracije $\mathrm{e}^{32,36}$.

\section{Bolesti neuromišićne spojnice - mijastenija gravis}

Disfagične smetnje u bolesnika s mijastenijom gravis uglavnom su prolaznog karaktera, a karakteristično napreduju tijekom procesa hranjenja ${ }^{2,4}$. Disfagija zahvaća 40 - $60 \%$ ovih bolesnika, a u njih $6-15 \%$ disfagija može biti prvi simptom bolesti ${ }^{37}$. Uglavnom se javlja zajedno s popratnim bulbarnim simptomima poput diplopije, ptoze, dizartrije i disfonije ${ }^{1}$.

Studije ukazuju na poremećenu oralnu, faringealnu i ezofagealnu fazu gutanja ${ }^{37-39}$. Kao najčešći poremećaj opisuje se odgođena faringealna faza gutanja, a uz nju se opisuju i poremećaji oralne faze gutanja u smislu poremećene formacije bolusa te otežanog žvakanja i potiskivanja hrane prema ždrijelu ${ }^{38}$. Poremećaji u procesu gutanja uočeni su i u onih bolesnika koji klinički nisu imali disfagične smetnje ${ }^{37,39}$. Uočeno je, naime, kako i bolesnici bez kliničkih simptoma imaju poremećaj ezofagealnog motiliteta ${ }^{37}$, a zahvaćeni, na supkliničkoj razini, mogu biti i submentalni i laringealni elevatori koji sudjeluju u procesu gutanja $^{39}$. Uočeno je kako aspirira i do $35 \%$ ovih bolesnika ${ }^{38}$.

lako se radi o načelno rijetkoj bolesti, koja uglavnom pogađa žene srednje životne dobi ${ }^{40}$, broj 
oboljelih u starijoj populaciji je u porastu. Simptomi bolesti mogu izrazito nalikovati simptomima Parkinsonove bolesti, moždanog udara i slično. Stoga pojava disfagije u starijih bolesnika s mijastenijom, osobito ako se radi o disfagiji kao jedinom simptomu bolesti, kliničara lako može navesti na krivi trag. To može biti izuzetno opasno jer nepravovremena dijagnoza povećava rizik od pojave mijastenične krize koja je, u svojoj osnovi, životno ugrožavajuće stanje ${ }^{41,42}$.

\section{Bolesti motornog neurona - amiotrofična lateralna skleroza}

Amiotrofična lateralna skleroza (ALS) progresivna je, neizlječiva, neurodegenerativna bolest uzrokovana propadanjem gornjih i donjih motoneurona u mozgu i kralježničnoj moždini. Prevalencija bolesti u Europi i Sjevernoj Americi iznosi oko $2,7 / 100000$. $\cup 70 \%$ oboljelih bolest se prvo prezentira spinalnim simptomima, u $25 \%$ bulbarnim simptomima, a u preostalih $5 \%$ respiratornim tegobama ${ }^{43}$.

Gubitak motorne funkcije mišića lica, jezika, ždrijela, grkljana i ostalih struktura uključenih u proces gutanja, postupno vodi do poremećene funkcije gutanja. Mišići jezika često su zahvaćeni više od ostalih pa se slabost mišića jezika u trenutku postavljanja dijagnoze navodi kao prognostički faktor preživljavanja oboljelih ${ }^{44-46}$.

Disfagija je učestali simptom kod bolesnika $s$ ALS-om. U 30 \% oboljelih disfagija može biti početni simptom bolesti, dok se s napredovanjem bolesti disfagija javi u oko $80 \%$ oboljelih ${ }^{47}$.

U studiji objavljenoj 2017. godine, koja je uključila 145 pacijenata s ALS-om, praćen je razvoj poremećaja gutanja u oboljelih tijekom dvije godine. $\mathrm{Na}$ početku studije disfagija je bila prisutna $u$ $95 \%$ bolesnika s bulbarnim oblikom bolesti i $35 \%$ bolesnika sa spinalnim oblikom bolesti, dok je nakon dvogodišnjeg perioda praćenja disfagija bila prisutna u $98 \%$ bolesnika s bulbarnim oblikom bolesti i $73 \%$ bolesnika sa spinalnim oblikom bolesti ${ }^{48}$.

U drugoj studiji, objavljenoj 2016. godine, koja je uključila 202 pacijenta s ALS-om, proučavan je odnos između stupnja disfagije i fiberendoskopske evaluacije gutanja. Stupanj disfagije određivan je pomoću Amyotrophic Lateral Sclerosis
Functioning Rating Scale (ALSFRS) i b-ALSFRS skale koja se koristi za procjenu stupnja bolesti u bolesnika s bulbarnim oblikom bolesti. Fiberendoskopski su promatrani parametri zaostatka rezidue nakon gutanja, preuranjenog izbacivanja bolusa te penetracije/aspiracije. Dokazano je na statistički značajnoj razini ( $p<0,0001$ ) kako postoji povezanost između stupnja bolesti i težine disfagije, u spinalnom i u bulbarnom obliku bolesti, neovisno o teksturi primijenjenog bolusa. Također, aspiracija je na statistički značajnoj razini $(p<0,0001)$ bila češća u bolesnika s težim stupnjem bolesti ${ }^{47}$.

Kliničke smjernice European ALS Consortiuma (EALSC) preporučuju ranu primjenu perkutane endoskopske gastrostome (PEG) u oboljelih od ALS-a, a vrijeme primjene trebalo bi biti bazirano na individualnom pristupu, uzimajući u obzir prisutnost bulbarnih simptoma, respiratornu funkciju, ukupno stanje bolesnika i parametre malnutricije (gubitak više od $10 \%$ tjelesne mase $)^{49}$. Studija objavljena 2011. koja je obuhvatila 150 bolesnika s ALS-om ili vjerojatnom dijagnozom ALS-a, od čega 62 s bulbarnim oblikom bolesti i 88 sa spinalnim oblikom bolesti, pratila je utjecaj postavljanja PEG-a na preživljenje ovih bolesnika. Bolesnici su praćeni do smrti ili trenutka kada je bilo potrebno učiniti traheostomu, a ukupno 76 njih prihvatilo je postavljanje PEG-a. Ova je studija dokazala da je postavljanje PEG-a sigurna procedura koja može produljiti život ovih bolesnika za barem šest mjeseci. Naime, median preživljavanja od trenutka početka simptoma bolesti iznosio je 38 mjeseci za oboljele koji su prihvatili postavljanje PEG-a i 32 mjeseca za one koji su odbili navedenu proceduru $(p=0,05)^{50}$.

\section{Ostali uzroci neurogene orofaringealne disfagije}

Kao ostali mogući uzroci neurogene orofaringealne disfagije ističu se tumori, ozljede i infekcije mozga, miopatije te jatrogeni uzroci. $U$ jatrogene uzroke ubraja se tardivna diskinezija koja nastaje kao posljedica terapije neurolepticima, potom disfagija koja nastaje kao posljedica kirurških zahvata u području vrata te disfagija kao komplikacija nakon aplikacije botulinskog toksina $u$ područje vrata u svrhu liječenja cervikalne distonije ili spastične disfonije $e^{1,5,6}$. 


\section{DIJAGNOSTIKA}

Neurološki bolesnici s disfagijom podliježu brojnim rizicima, kao što su aspiracija i aspiracijska pneumonija, dehidracija i pothranjenost. Otežano im je uzimanje lijekova oralnim putem i značajno im je smanjena cjelokupna kvaliteta života ${ }^{4-6}$. Kao poseban entitet ističe se tiha aspiracija do koje dolazi bez popratnih upozoravajućih simptoma, a najčešće se javlja kada prilikom subglotičnog zadržavanja stranog materijala izostane zaštitni refleks kašlja ${ }^{51}$.

Zbog svega navedenog, izrazito je važna pravovremena dijagnoza disfagije koja vodi što ranijem procesu liječenja i rehabilitacije $e^{4-6}$. U svakodnevnoj kliničkoj praksi potrebno je obratiti pažnju na simptome koji ukazuju na povećan rizik od aspiracije, a to su dizartrije, disfonije, nevoljni kašalj, abnormalan ili odsutan refleks kašlja koji se javlja nakon gutanja te promjena glasa nakon gutanja ${ }^{52}$. Rizik od pojave disfagije je nakon kliničkog pregleda moguće dodatno utvrditi testovima probira, a jedan od njih jest Eating assesment tool (EAT-10). EAT-10 je test koji se sastoji od 10 tvrdnji za samoprocjenu simptoma disfagije, a svaku je tvrdnju moguće bodovati brojevima od 0 do 4, gdje 0 označava odsustvo teškoća, a 4 značajne teškoće. Zbroj bodova danih za sve tvrdnje u testu koji iznosi 3 ili više upućuje na prisutnost problema s gutanjem. Test se koristi za procjenu težine simptoma, učinaka terapije i kvalitete života, a preveden je na mnoge svjetske jezike. Više studija provedenih u raznim državama Europe dokazalo je njegovu valjanost i pouzdanost ${ }^{53-55}$. Procjena švedske inačice ovog testa, pokazala je 98,5\% njegove osjetljivosti i 94,1 \% specifično$s t^{53}$, a procjena francuske inačice testa ukazala je na značajnu opasnost od aspiracije u bolesnika sa zbrojem bodova 17 i više ${ }^{55}$. Ovaj je test preveden i na hrvatski jezik, a Smjernice za rano prepoznavanje, dijagnostiku i terapiju neurogene orofaringealne disfagije uz njega navode i Prilagođeno ispitivanje gutanja (MSA - Modified swallowing assesment) kao pogodan test probira. Smjernice, nadalje, navode kako neurolog ili logoped daljnju obradu bolesnika nužno trebaju učiniti u roku od 72 sata nakon postavljanja indikacije pomoću provedenog testa probira. Bolesnika je do njiho- vog dolaska potrebno održavati na način da ne uzima ništa na usta. Ukoliko daljnji dijagnostički proces nije moguće provesti u roku od 72 sata, pacijentu se do nastavka dijagnostičkog postupka postavlja nazogastrična sonda ${ }^{4}$.

Opisani su i brojni „testovi uz krevet“ koji pomažu u brzoj identifikaciji bolesnika s disfagijom već u prvim kontaktima sa stručnim timom, a provode se i u procesu logopedske dijagnostike. Neki od njih jesu Volume-viscosity swalloving test (V-VST) čija se osjetljivost procjenjuje na $69-100 \%$, a spe-

Neurološke bolesnike s disfagijom važno je pravovremeno uključiti u proces logopedske terapije, a postoje naznake kako bi kombiniranje logopedske terapije $s$ neuromišićnom električnom stimulacijom moglo dodatno poboljšati ishode rehabilitacijskog postupka. Predmet novijih istraživanja jest i duboka mozgovna stimulacija, odnosno njezin učinak na liječenje disfagije u oboljelih od Parkinsonove bolesti.

cifičnost na $29-87 \%$, potom Toronto bedside swalloving screening test (TOR-BSST) čija je osjetljivost $80-96 \%$, a specifičnost $64-68 \%$, Water test s osjetljivošću 95 - $98 \%$ i specifičnošću 48 $49 \%$ te Cough test osjetljivosti $79 \%$ i specifičnosti $59 \%{ }^{56}$. Smjernice za rano prepoznavanje, dijagnostiku i terapiju neurogene orofaringealne disfagije sugeriraju korištenje V-VST i Water testa u procesu logopedske dijagnostike te bodovanje dobivenih rezultata uz pomoć Funkcionalne oralne ljestvice unosa (FOIS - Functional oral intake scale), Ljestvice ishoda i težine disfagije (DOSS The dysphagia outcome and severity scale) i Ljestvice težine disfagije (DSS - Dysphagia severity score $)^{4}$.

Zlatnim standardom u dijagnostici disfagije smatra se videofluoroskopija. To je pretraga koja omogućava prikaz cijelog akta gutanja. Njome je moguće prikazati orofaringealni trakt, gornji ezofagealni sfinkter i jednjak ${ }^{57}$. Međutim, prilikom izvođenja ove pretrage u bolesnika s disfagijom potreban je oprez zbog mogućih komplikacija koje, između ostalog, uključuju proljeve, hipovolemijski šok i aspiraciju koja može dovesti do fatalnog edema pluća ${ }^{58,59}$. Zbog praktičnih razloga sve se više upotrebljava fiberendoskopska evalu- 
acija gutanja ${ }^{4-6}$. Kao prednosti fiberendoskopske evaluacije gutanja ističu se mogućnost obavljanja pretrage uz postelju bolesnika, izbjegavanje zračenja te mogućnost jednostavnog ponavljanja pretrage u više navrata, a komplikacije kao što su epistaksa i vazovagalna sinkopa su rijetke ${ }^{60,61}$. Fiberendoskopijom je moguće prikazati područje ždrijela i grkljana u trenutku neposredno prije i neposredno nakon gutanja. $U$ samom trenutku gutanja, prikaz nije moguć zbog kontrakcije muskulature koja dovodi do kontakta sluznice s endoskopom ${ }^{62}$.

Jedno istraživanje koje je obuhvatilo osam zdravih muškaraca u dobi od 21 do 29 godina, promatralo je mogućnost prikaza 12 elemenata gutanja uz pomoć videofluoroskopije odnosno fiberendoskopije. Promatrani su oralni prijenos, faringealni prijenos, faringealna odgoda gutanja, laringealna elevacija, kontakt epiglotisa sa stražnjim faringealnim zidom, pokreti hioida, zatvaranje larinksa na ulazu u dišni put, krikofaringealni otvor, kontakt baze jezika sa stražnjim faringealnim zidom, pokreti aritenoidnih hrskavica, zatvaranje na razini aritenoida, zatvaranje rime glotidis. Pokazalo se kako je pokrete hioida, zatvaranje larinksa na ulazu u dišni put, krikofaringealni otvor i kontakt baze jezika sa stražnjim faringealnim zidom bilo moguće prikazati samo videofluoroskopijom, ali ne i fiberendoskopskom evaluacijom gutanja63.

Novija istraživanja ukazuju na to kako fiberendoskopska evaluacija gutanja može biti korisna u prilagodbi prehrambenih režima neuroloških bolesnika s disfagijom. Promjenom prehrane na osnovi nalaza fiberendoskopske evaluacije gutanja, u ovih je bolesnika moguće smanjiti stopu upale pluća ( $36 \%$ u odnosu na $50 \%, p=0,051$ ) i mortalitet $(3,7 \%$ u odnosu na $11,3 \%, p=0,043)$ u usporedbi s bolesnicima kojima nije mijenjan režim prehrane ${ }^{64}$.

Bazalna oralna disfagija (OR: 2,72; $p=0,010$ ) i narušena funkcija gutanja (OR: 2,$73 ; p=0,015$ ) prepoznate su kao značajni rizični faktori za razvoj malnutricije u starijoj populaciji65. Stoga je u ovih bolesnika tijekom dijagnostičke obrade nužna i procjena nutritivnog statusa. Smjernice za rano prepoznavanje, dijagnostiku i terapiju neurogene orofaringealne disfagije preporučuju korištenje sljedećih testova probira: Nutrition Risk Scree- ning 2002 (NRS-2002), Mini Nutritional Assesment (MNA) i Malnutrition Universal Screening Tool (MUST) $)^{4}$.

\section{LIJEČENJE I REHABILITACIJA}

Bolesnicima s disfagijom nužno je odmah korigirati i prilagoditi prehranu te konstantno voditi računa o hidraciji. Prilagodba prehrane podrazumijeva određivanje idealne konzistencije hrane i modifikaciju bolusa, a jelovnike je potrebno planirati na način da se zadovolje sve energetske potrebe bolesnika. Katkad, u akutnim fazama nakon moždanog udara, bolesnike je privremeno potrebno hraniti putem nazogastrične sonde, a u slučaju duljeg trajanja simptoma poseže se i za postavljanjem PEG-a ${ }^{4,6,66}$.

$U$ procesu logopedske terapije uče se specifične tehnike sigurnog gutanja koje se, između ostalog, zasnivaju na promjeni položaja tijela i glave. Prema dostupnim podatcima, promjenom položaja tijela i glave moguće je prevenirati aspiraciju u preko $70 \%$ bolesnika s disfagijom. Za postizanje što boljih rezultata potrebno je kontrolirati volumen bolusa, a lošiji ishodi uočeni su u bolesnika sa smanjenim opsegom pokreta glave, složenijim poremećajima gutanja te narušenom kognitivnom funkcijom ${ }^{67,68}$. Nadalje, u logopedskoj je terapiji moguće koristiti i manevre sigurnog gutanja. Neki od njih jesu Mendelsohnov manevar kojim je moguće larinks držati podignutim 3-5 sekundi nakon gutanja69 ${ }^{69}$ Effortfull swallowing kojim se ubrzavaju vertikalni pokreti hioidne kosti ${ }^{70}$ te supraglottic swallowing kojim se postiže približavanje vokalnih nabora i aritenoida ${ }^{71}$. Prije i za vrijeme provođenja rehabilitacijskih postupaka iznimno je važno voditi računa o higijeni oralne šupljine ${ }^{4}$.

Podatci kazuju da se u bolesnika u kojih je disfagija nastala kao posljedica moždanog udara, provedbom logopedske terapije postiže poboljšanje funkcije gutanja za prosječno 22 dana u 84,26\% ispitanika ${ }^{72}$.

Nadalje, simptomi disfagije mogu biti smanjeni i olakšani provođenjem specifičnih vježbi za jačanje jezičnih, infrahioidnih i faringealnih mišića. Takvim se vježbama može utjecati na neuroplastičnost mozga te poticati jačanje i stvaranje novih sinaptičkih puteva koji sudjeluju u procesu 
gutanja, što postupno vodi djelomičnom poboljšanju simptoma. Kao korisna u rehabilitacijskom procesu navodi se i neuromišićna električna stimulacija ${ }^{6,73,74}$. Pokazalo se kako je u bolesnika s disfagijom nakon moždanog udara terapija koja je uključivala neuromišićnu električnu stimulaciju, bila učinkovitija od one u kojoj ona nije korištena. Isto istraživanje, međutim, nije dokazalo da je neuromišićna električna stimulacija sama po sebi učinkovitija od klasičnih metoda koje se koriste $u$ rehabilitacijskom postupku disfagija ${ }^{75}$.

Katkada se može pokušati bolesnike tretirati kirurškim metodama poput krikofaringealne miotomije, a relaksaciju krikofaringealnog mišića moguće je postići i aplikacijom botulinskog toksina ${ }^{6,76}$.

lako zasad nema dovoljno velikih kliničkih studija, neki autori ističu kako bi primjena duboke mozgovne stimulacije u budućnosti mogla imati značajnu ulogu u tretmanu neurogene orofaringealne disfagije. Naročito se istražuje njezin utjecaj na liječenje disfagije u oboljelih od Parkinsonove bolesti jer je dokazan učinak te metode na mnoge motoričke simptome ${ }^{11,77}$.

\section{ZAKLJUČAK}

Pregledom recentne literature vidljivo je da je disfagija često prisutna kod neuroloških oboljenja te je čest uzrok različitih komplikacija, produljenog i otežanog liječenja neuroloških bolesnika, posebno ako se ne prepozna na vrijeme. $U$ današnje vrijeme, prije sofisticiranih i zahtjevnih pretraga može se vrlo lako, bezbolno i na vrijeme dijagnosticirati disfagija neuroloških bolesnika „testovima uz krevet“ koji se nedovoljno primjenjuju. Edukacija multidisciplinarnih timova, posebno medicinskih sestara, o tim testovima dovela bi do toga da se prevencija, terapija i rehabilitacija bolesnika primijene na vrijeme te se spriječe moguće komplikacije i poboljšaju ishodi i kvaliteta života neuroloških bolesnika. U svakom slučaju, pristup i liječenje disfagije neuroloških bolesnika treba biti multidisciplinarno i vođeno smjernicama stručnih društava. Nove metode, poput dubinske mozgovne stimulacije, obećavajuće su kod nekih neuroloških oboljenja kompliciranih disfagijom, poput Parkinsonove bolesti.

Izjava o sukobu interesa: Autori izjavljuju kako ne postoji sukob interesa.

\section{LITERATURA}

1. Kumar S. Swallowing and dysphagia in neurological disorders. Rev Neurol Dis 2010;7:19-27.

2. Guyton AC, Hall JE. Medicinska fiziologija. 12. izdanje. Zagreb: Medicinska naklada, 2012;763-765.

3. Fairfield CA, Smithard DG. Assesment and management of dysphagia in acute stroke: an initial service review of international practice. Geriatrics (Basel) [Internet]. 2020;5:4. [cited 2020 Apr 12]. Available from: https:// www.ncbi.nlm.nih.gov/pmc/articles/PMC7151229/.

4. Poljaković Z, Vodanović D, Vranešić Bender D, Ljubas Kelečić D, Starčević K, Kolundžić $Z$ et al. Smjernice za rano prepoznavanje, dijagnostiku i terapiju neurogene orofaringealne disfagije. Liječ Vjesn [Internet]. 2017;139: 0-0. [cited 2020 Apr 12]. Available from: https://hrcak. srce.hr/187270.

5. Daniels SK. Neurological disorders affecting oral, pharyngeal swallowing. GI Motility online [Internet]. 2006. [cited 2020 May 2]. Available from: https://www.nature. com/gimo/contents/pt1/full/gimo34.html.

6. Bakheit AM. Managment of neurogenic dysphagia. Postgrad Med J 2001;77:694-699.

7. Cohen DL, Roffe C, Beavan J, Blackett B, Fairfield CA, Hamdy $S$ et al. Post-stroke dysphagia: a review and design considerations for future trials. Int J Stroke 2016;11: 399-411.

8. Takizawa C, Gemmell E, Kenworthy J, Speyer R. A systematic review of the prevalence of oropharyngeal dysphagia in stroke, Parkinson's disease, Alzheimer's disease, head injury, and pneumonia. Dysphagia [Internet]. 2016;31:434-41. [cited 2020 May 2]. Available from: https://link.springer.com/article/10.1007/s00455016-9695-9.

9. Daniels SK, Huckabee ML, Gozdzikowska K. Dysphagia following stroke. $3^{\text {th }}$ Edition. San Diego: Plural Publishing Inc, 2019;6-8.

10. Eltringham SA, Kilner K, Gee M, Sage K, Bray BD, Pownall S et al. Impact of dysphagia assessment and management on risk of stroke-associated pneumonia: a systematic review. Cerebrovasc Dis 2018;46:99-107.

11. Ho CH, Lin WC, Hsu YF, Lee IH, Hung YC. One-Year Risk of Pneumonia and Mortality in Patients with Poststroke Dysphagia: A Nationwide Population-Based Study. J Stroke Cerebrovasc Dis [Internet]. 2018;27:1311-1317. [cited 2020 Oct 5]. Available from: https://www.strokejournal. org/article/S1052-3057(17)30680-8/fulltext.

12. Suttrup I, Warnecke T. Dysphagia in Parkinson's Disease. Dysphagia [Internet]. 2016;31:24-32. [cited 2020 May 2]. Available from: https://link.springer.com/article/10.1007/ s00455-015-9671-9.

13. Müller J, Wenning GK, Verny M, McKee A, Chaudhuri KR, Jellinger $\mathrm{K}$ et al. Progression of dysarthria and dysphagia in postmortem-confirmed parkinsonian disorders. Arch Neurol 2001;58:259-64.

14. Robbins JA, Logemann JA, Kirshner HS. Swallowing and speech production in Parkinson's disease. Ann Neurol 1986;19:283-7.

15. Hammer MJ, Murphy CA, Abrams TM. Airway somatosensory deficits and dysphagia in Parkinson's disease. J Parkinsons Dis 2013;3:39-44.

16. Hegland KW, Okun MS, Troche MS. Sequential voluntary cough and aspiration or aspiration risk in Parkinson's 
disease. Lung [Internet]. 2014;192:601-8. [cited 2020 May 3]. Available from: https://www.ncbi.nlm.nih.gov/pmc/ articles/PMC4740922/.

17. Setzen M, Cohen MA, Perlman PW, Belafsky PC, Guss J, Mattucci KF et al. The association between laryngopharyngeal sensory deficits, pharyngeal motor function, and the prevalence of aspiration with thin liquids. Otolaryngol Head Neck Surg 2003;128:99-102.

18. Tomita S, Oeda T, Umemura A, Kohsaka M, Park K, Yamamoto $K$ et al. Video-fluoroscopic swallowing study scale for predicting aspiration pneumonia in Parkinson's disease. PLoS One 2018;13:e0197608.

19. Fujioka S, Fukae J, Ogura H, Mishima T, Yanamoto S, Higuchi MA et al. Hospital-based study on emergency admission of patients with Parkinson's disease. eNeurologicalSci [Internet]. 2016;4:19-21. [cited 2020 May 3]. Available from: https://www.ncbi.nlm.nih.gov/ pmc/articles/PMC5803112/.

20. Beyer MK, Herlofson K, Arsland D, Larsen JP. Causes of death in a community-based study of Parkinson's disease. Acta Neurol Scand 2001;103:7-11.

21. Monteiro L, Souza-Machado A, Valderramas S, Melo A. The effect of levodopa on pulmonary function in Parkinson's disease: a systematic review and meta-analysis. Clin Ther [Internet]. 2012;34:1049-55. [cited 2020 May 3]. Available from: https://www.clinicaltherapeutics. com/article/S0149-2918(12)00146-4/fulltext.

22. Williams-Gray $\mathrm{CH}$, Mason SL, Evans JR, Foltynie T, Brayne C, Robbins TW et al. The CamPalGN study of Parkinson's disease: 10-year outlook in an incident population-based cohort. J Neurol Neurosurg Psychiatry [Internet]. 2013;84:1258-64. [cited 2020 May 3]. Available from: https://jnnp.bmj.com/content/84/11/1258.full.

23. Clark HM, Stierwalt JAG, Tosakulwong N, Botha H, Ali F, Whitwell JL et al. Dysphagia in Progressive Supranuclear Palsy. Dysphagia [Internet]. 2020;35:667-676. [cited 2020 May 3]. Available from: https://link.springer.com/ article/10.1007/s00455-019-10073-2.

24. Abdelhamid A, Bunn D, Copley M, Cowap V, Dickinson A, Gray $L$ et al. Effectiveness of interventions to directly support food and drink intake in people with dementia: systematic review and meta-analysis. BMC Geriatr 2016;16:26.

25. Alagiakrishnan K, Bhanji RA, Kurian M. Evaluation and management of oropharyngeal dysphagia in different types of dementia: a systematic review. Arch Gerontol Geriatr [Internet]. 2013;56:1-9. [cited 2020 May 3]. Available from: https://www.sciencedirect.com/science/ article/abs/pii/S0167494312000970?via\%3Dihub.

26. Affoo RH, Foley N, Rosenbek J, Shoemaker JK, Martin RE. Swallowing dysfunction and autonomic nervous system dysfunction in Alzheimer's disease: a scoping review of the evidence. J Am Geriatr Soc 2013;61:2203-13.

27. Boccardi V, Ruggiero C, Patriti A, Marano L. Diagnostic assessment and management of dysphagia in patients with Alzheimer's disease. J Alzheimers Dis 2016;50:94755.

28. Chouinard J. Dysphagia in Alzheimer disease: a review. J Nutr Health Aging 2000;4:214-7.

29. Suh MK, Kim H, Na DL. Dysphagia in patients with dementia: Alzheimer versus vascular. Alzheimer Dis Assoc Disord 2009;23:178-84.

30. Alagiakrishnan K, Bhanji RA, Kurian M. Evaluation and management of oropharyngeal dysphagia in different types of dementia: a systematic review. Arch Gerontol Geriatr [Internet]. 2013;56:1-9. [cited 2020 May 3]. Available from: https://www.sciencedirect.com/science/ article/abs/pii/S0167494312000970?via\%3Dihub.

31. Aghaz A, Alidad A, Hemmati E, Jadidi H, Ghelichi L. Prevalence of dysphagia in multiple sclerosis and its related factors: Systematic review and meta-analysis. Iran J Neurol 2018;17:180-188.

32. Ansari NN, Tarameshlu M, Ghelichi L. Dysphagia In multiple sclerosis patients: diagnostic and evaluation strategies. Degener Neurol Neuromuscul Dis [Internet]. 2020;10:15-28. [cited 2020 May 5]. Available from: https://www.ncbi.nIm.nih.gov/pmc/articles/ PMC7114936/.

33. Tassorelli C, Bergamaschi R, Buscone S, Bartolo M, Furnari $A$, Crivelli $P$ et al. Dysphagia in multiple sclerosis: from pathogenesis to diagnosis. Neurol Sci 2008;29: S360-3.

34. Milewska M, Grabarczyk K, Dąbrowska-Bender M, Jamróz B, Dziewulska D, Staniszewska et al. The prevalence and types of oral- and pharyngeal-stage of dysphagia in patients with demyelinating diseases based on subjective assessment by the study subjects. Mult Scler Relat Disord [Internet]. 2020;37:101484. [cited 2020 May 5]. Available from: https://www.msard-journal.com/article/S22110348(19)30473-0/fulltext.

35. Alali D, Ballard K, Bogaardt $\mathrm{H}$. The frequency of dysphagia and its impact on adults with multiple sclerosis based on patient-reported questionnaires. Mult Scler Relat Disord [Internet]. 2018;25:227-231. [cited 2020 May 5]. Available from: https://www.msard-journal.com/article/S22110348(18)30270-0/fulltext.

36. Alali $D$, Ballard K, Bogaardt $H$. Treatment effects for dysphagia in adults with multiple sclerosis: a systematic review. Dysphagia [Internet]. 2016;31:610-8. [cited 2020 May 5]. Available from: https://link.springer.com/ article/10.1007/s00455-016-9738-2.

37. Umay EK, Karaahmet F, Gurcay E, Balli F, Ozturk E, Karaahmet $O$ et al. Dysphagia in myasthenia gravis: the tip of the Iceberg. Acta Neurol Belg [Internet]. 2018;118:259266. [cited 2020 May 5]. Available from: https://link. springer.com/article/10.1007\%2Fs13760-018-0884-1.

38. Colton-Hudson A, Koopman WJ, Moosa T, Smith D, Bach D, Nicolle M. A prospective assessment of the characteristics of dysphagia in myasthenia gravis. Dysphagia 2002;17: 147-51.

39. Ertekin C, Yüceyar N, Aydogdu I. Clinical and electrophysiological evaluation of dysphagia in myasthenia gravis. J Neurol Neurosurg Psychiatry 1998;65:848-56.

40. Altman KW, Richards A, Goldberg L, Frucht S, McCabe DJ. Dysphagia in stroke, neurodegenerative disease, and advanced dementia. Otolaryngol Clin North Am [Internet]. 2013;46:1137-49. [cited 2020 May 5]. Available from: https://www.sciencedirect.com/science/article/abs/pii/ S0030666513001084?via\%3Dihub.

41. Kim SJ, Park GY, Choi YM, Sohn DG, Kang SR, Im S. Bulbar myasthenia gravis superimposed in a medullary infarction diagnosed by a fiberoptic endoscopic evaluation of swallowing with simultaneous tensilon application. Ann Rehabil Med [Internet]. 2017;41:1082-1087. [cited 2020 May 5]. Available from: https://www.ncbi.nlm.nih.gov/ pmc/articles/PMC5773429/.

42. Klair JS, Rochlani YM, Meena NK. Myasthenia gravis masquerading as dysphagia: unveiled by magnesium infusion. BMJ Case Rep 2014;2014:bcr2014204163. 
43. Zarei S, Carr K, Reiley L, Diaz K, Guerra O, Altamirano PF et al. A comprehensive review of amyotrophic lateral sclerosis. Surg Neurol Int [Internet]. 2015;6:171. [cited 2020 Oct 10]. Available from: https://www.ncbi.nlm.nih. gov/pmc/articles/PMC4653353/.

44. DePaul R, Brooks BR. Multiple orofacial indices in amyotrophic lateral sclerosis. J Speech Hear Res 1993;36:1158-67.

45. Luchesi KF, Kitamua S, Mourão LF. Amyotrophic Lateral Sclerosis survival analysis: Swallowing and non-oral feeding. NeuroRehabilitation 2014;35:535-42.

46. Weikamp JG, Schelhaas HJ, Hendriks JC, de Swart BJ, Geurts AC. Prognostic value of decreased tongue strength on survival time in patients with amyotrophic lateral sclerosis. J Neurol [Internet]. 2012;259:2360-5. [cited 2020 Oct 10]. Available from: https://www.ncbi.nlm.nih. gov/pmc/articles/PMC3484270/.

47. Fattori B, Siciliano G, Mancini V, Bastiani L, Bongioanni P, Caldarazzo lenco E et al. Dysphagia in Amyotrophic Lateral Sclerosis: Relationships between disease progression and Fiberoptic Endoscopic Evaluation of Swallowing. Auris Nasus Larynx [Internet]. 2017;44:306-312. [cited 2020 Oct 10]. Available from: https://www.aurisnasuslarynx. com/article/S0385-8146(16)30202-4/fulltext.

48. Onesti E, Schettino I, Gori MC, Frasca V, Ceccanti M, Cambieri $C$ et al. Dysphagia in Amyotrophic Latera Sclerosis: Impact on Patient Behavior, Diet Adaptation, and Riluzole Management. Front Neurol [Internet]. 2017;8:94. [cited 2020 Oct 10]. Available from: https:// www.ncbi.nlm.nih.gov/pmc/articles/PMC5359548/.

49. Andersen PM, Borasio GD, Dengler R, Hardiman O, Kollewe K, Leigh PN et al. Good practice in the management of amyotrophic lateral sclerosis: clinical guidelines. An evidence-based review with good practice points. EALSC Working Group. Amyotroph Lateral Scler 2007;8:195-213.

50. Spataro R, Ficano L, Piccoli F, La Bella V. Percutaneous endoscopic gastrostomy in amyotrophic lateral sclerosis: effect on survival. J Neurol Sci [Internet]. 2011;304:44-8. [cited 2020 Oct 10]. Available from: https://www.jnsjournal.com/article/S0022-510X(11)00071-2/fulltext.

51. Lee JY, Kim DK, Seo KM, Kang SH. Usefulness of the simplified cough test in evaluating cough reflex sensitivity as a screening test for silent aspiration. Ann Rehabil Med [Internet]. 2014;38:476-84. [cited 2020 May 10]. Available from: https://www.ncbi.nlm.nih.gov/pmc/articles/ PMC4163587/.

52. Daniels SK, McAdam CP, Brailey K, Foundas AL. Clinical assessment of swallowing and prediction of dysphagia severity. Am J Speech Lang Pathol 1997;6:17-24

53. Möller R, Safa S, Östberg P. Validation of the Swedish translation of eating assessment tool (S-EAT-10). Acta Otolaryngol [Internet]. 2016;136:749-753. [cited 2020 May 10]. Available from: https://www.tandfonline.com/ doi/full/10.3109/00016489.2016.1146411.

54. Printza A, Kyrgidis A, Pavlidou E, Triaridis S, Constantinidis J. Reliability and validity of the Eating Assessment Tool-10 (Greek adaptation) in neurogenic and head and neck cancer-related oropharyngeal dysphagia. Eur Arch Otorhinolaryngol [Internet]. 2018;275:1861-1868. [cited 2020 May 10]. Available from: https://link.springer.com/ article/10.1007/s00405-018-5001-9.

55. Lechien JR, Cavelier G, Thill MP, Huet K, Harmegnies B, Bousard $L$ et al. Validity and reliability of the French version of Eating Assessment Tool (EAT-10). Eur Arch Otorhinolaryngol [Internet]. 2019;276:1727-1736. [cited 2020 May 10]. Available from: https://link.springer.com/ar ticle/10.1007\%2Fs00405-019-05429-1.

56. Kertscher B, Speyer R, Palmieri M, Plant C. Bedside screening to detect oropharyngeal dysphagia in patients with neurological disorders: an updated systematic review. Dysphagia [Internet]. 2014;29:204-212. [cited 2020 May 10]. Available from: https://link.springer.com/article/10.1 007\%2Fs00455-013-9490-9.

57. Oliver D, Borasio GD, Walsh D. Palliative Care in Amyotrophic Lateral Sclerosis: from Diagnosis to Bereavement. $2^{\text {nd }}$ Edition. Oxford: Oxford University Press, 2006;95-109.

58. Tsokos M, Schulz F, Vogel H. Bariumaspiration mit Todesfolge [Barium aspiration with fatal outcome]. Aktuelle Radiol 1998;8:201-3.

59. Miyazawa T, Sho C, Nakagawa H, Oshino N. Effect of watersoluble contrast medium on the lung in rats. Comparison of iotrolan, iopamidol, and diatrizoate. Invest Radiol 1990;25:999-1003.

60. Braun T, Juenemann M, Viard M, Meyer M, Reuter I, Prosiegel $\mathrm{M}$ et al. Adjustment of oral diet based on flexible endoscopic evaluation of swallowing (FEES) in acute stroke patients: a cross-sectional hospital-based registry study. BMC Neurol [Internet]. 2019;19:282. [cited 2020 May 6]. Available from: https://www.ncbi.nlm.nih.gov/pmc/ articles/PMC6852733/.

61. Kühnlein P, Gdynia $H J$, Sperfeld $A D$, Lindner-Pfleghar $B$, Ludolph AC, Prosiegel $\mathrm{M}$ et al. Diagnosis and treatment of bulbar symptoms in amyotrophic lateral sclerosis. Nat Clin Pract Neurol [Internet]. 2008;4:366-74. [cited 2020 Oct 11]. Available from: https://www.nature.com/articles/ ncpneuro0853.

62. Langmore SE. Endoscopic Evaluation and Treatment of Swallowing Disorders. $2^{\text {nd }}$ Edition. New York: Thieme, 2000;37-61.

63. Logemann JA, Rademaker AW, Pauloski BR, Ohmae Y, Kahrilas PJ. Normal swallowing physiology as viewed by videofluoroscopy and videoendoscopy. Folia Phoniatr Logop 1998;50:311-9.

64. Braun $\mathrm{T}$, Juenemann $\mathrm{M}$, Viard M, Meyer M, Fuest $\mathrm{S}$, Reuter I et al. What is the value of fibre-endoscopic evaluation of swallowing (FEES) in neurological patients? A crosssectional hospital-based registry study. BMJ Open [Internet]. 2018;8:e019016. [cited 2020 Oct 11]. Available from: https://www.ncbi.nlm.nih.gov/pmc/articles/ PMC5855308/.

65. Fávaro-Moreira NC, Krausch-Hofmann S, Matthys C, Vereecken C, Vanhauwaert E, Declercq A et al. Risk factors for malnutrition in older adults: a systematic review of the literature based on longitudinal data. Adv Nutr 2016;7: 507-22.

66. Newman R, Vilardell N, Clavé P, Speyer R. Effect of bolus viscosity on the safety and efficacy of swallowing and the kinematics of the swallow response in patients with oropharyngeal dysphagia: White paper by the European society for swallowing disorders (ESSD). Dysphagia [Internet]. 2016;31:232-249. [cited 2020 May 10]. Available from: https://www.ncbi.nlm.nih.gov/pmc/ articles/PMC4929168/.

67. Ohmae $\mathrm{Y}$, Karaho $\mathrm{T}$, Hanyu $\mathrm{Y}$, Murase $\mathrm{Y}$, Kitahara $\mathrm{S}$, Inouye T. [Effect of posture strategies on preventing aspiration]. Nihon Jibiinkoka Gakkai Kaiho 1997;100:220-6. 
68. Rasley A, Logemann JA, Kahrilas PJ, Rademaker AW, Pauloski BR, Dodds WJ. Prevention of barium aspiration during videofluoroscopic swallowing studies: value of change in posture. AJR Am J Roentgenol 1993;160:1005-9.

69. Kim JH, Kim YA, Lee HJ, Kim KS, Kim ST, Kim TS et al. Effect of the combination of Mendelsohn maneuver and effortful swallowing on aspiration in patients with dysphagia after stroke. J Phys Ther Sci [Internet]. 2017;29:1967-1969. [cited 2020 May 10]. Available from: https://www.ncbi. nlm.nih.gov/pmc/articles/PMC5702826/.

70. Jang HJ, Leigh JH, Seo HG, Han TR, Oh BM. Effortful swallow enhances vertical hyolaryngeal movement and prolongs duration after maximal excursion. J Oral Rehabil [Internet]. 2015;42:765-773. [cited 2020 May 10]. Available from: https://onlinelibrary.wiley.com/doi/ abs/10.1111/joor.12312.

71. Bülow M, Olsson R, Ekberg O. Videomanometric analysis of supraglottic swallow, effortful swallow, and chin tuck in healthy volunteers. Dysphagia 1999;14:67-72.

72. Andrade JS, Souza WWOJ, Paranhos LR, Domenis DR, César CPHAR. [Effects of speech therapy in hospitalized patients with post-stroke dysphagia: a systematic review of observational studies]. Acta Med Port [Internet]. 2017;30:870-881. [cited 2020 May 10]. Available from: https://www.actamedicaportuguesa.com/revista/index. php/amp/article/view/9183.

73. Crary MA, Carnaby GD, LaGorio LA, Carvajal PJ. Functional and physiological outcomes from an exercise-based dysphagia therapy: a pilot investigation of the McNeill dysphagia therapy program. Arch Phys Med Rehabil [Internet]. 2012;93:1173-8. [cited 2020 May 10]. Available from: https://www.archives-pmr.org/article/S00039993(11)00972-5/fulltext.

74. Carnaby GD, LaGorio L, Silliman S, Crary M. Exercise-based swallowing intervention (McNeill dysphagia therapy) with adjunctive NMES to treat dysphagia post-stroke: a doubleblind placebo-controlled trial. J Oral Rehabil [Internet]. 2020;47:501-510. [cited 2020 May 10]. Available from: https://onlinelibrary.wiley.com/doi/abs/10.1111/ joor.12928.

75. Chen YW, Chang $\mathrm{KH}$, Chen $\mathrm{HC}$, Liang WM, Wang $\mathrm{YH}$, Lin YN. The effects of surface neuromuscular electrical stimulation on post-stroke dysphagia: a systemic review and meta-analysis. Clin Rehabil [Internet]. 2016;30:24-35. [cited 2020 May 11]. Available from: https://journals. sagepub.com/doi/10.1177/0269215515571681?url_ ver=Z39.88-2003\&rfr_id=ori:rid:crossref.org\&rfr_dat=cr_ pub\%20\%200pubmed.

76. Poirier NC, Bonavina L, Taillefer R, Nosadini A, Peracchia A, Duranceau A. Cricopharyngeal myotomy in neurogenic oropharyngeal dysphagia. J Thorac Cardiovasc Surg 1997; 113:233-40; discussion 240-1.

77. Olchik MR, Ghisi M, Ayres A, Schuh AFS, Oppitz PP, Rieder CRM. The impact of deep brain stimulation on the quality of life and swallowing in individuals with Parkinson's disease. Int Arch Otorhinolaryngol [Internet]. 2018;22: 125-129. [cited 2020 May 11]. Available from: https:// www.ncbi.nlm.nih.gov/pmc/articles/PMC5882365/. 